\title{
GERMINAÇÃO E DESENVOLVIMENTO PÓS-SEMINAL DE TIBOUCHINA MORICANDIANA (DC) Baill. (MELASTOMATACEAE) $^{1}$
}

\author{
Antonio Carlos Silva de Andrade 2 \\ Tânia Sampaio Pereira²
}

Entregue em 9.5.94. Aceito em 6.11.94.

\begin{abstract}
RESUMO - (Germinação e desenvolvimento pós-seminal de Tibouchina moricandiana (DC) Baill. (Melastomataceae). Estudou-se o efeito de diferentes temperaturas $\left(20,25,30,35\right.$ e $\left.30-20^{\circ} \mathrm{C}\right)$ sob condição de luz (fotoperíodo de oito horas) e escuro sobre a germinação de sementes de Tibouchina moricandiana (DC) Baill. Posteriormente, estudou-se a morfologia do desenvolvimento pós-seminal, visando o conhecimento das estruturas essenciais da plântula. Os resultados demonstraram que a temperatura ótima para a germinação de sementes foi de $30^{\circ} \mathrm{C}$; as temperaturas de 20 e $35^{\circ} \mathrm{C}$ causaram o decréscimo da porcentagem e da velocidade de germinação. As sementes são tipicamente fotoblásticas positivas, necessitando de vários dias de exposição a luz para alcançar a máxima germinação. O estudo do desenvolvimento pós-seminal permitiu classificar a plântula como faneroepígea, típica de espécies colonizadoras de grandes clareiras.
\end{abstract}

Palavras-chaves: Germinação, temperatura, luz, plântula.

ABSTRACT - (Germination and post-seminal development of Tibouchina moricandiana (DC) Baill. (Melastomataceae). The germination responses of Tibouchina moricandiana (DC) Baill. were tested under different temperature $\left(20,25,30,35\right.$ and $\left.30-20^{\circ} \mathrm{C}\right)$ and light regime (8 hours photoperiod or darkness). A morphological study of the post-seminal development was carried out to establish descriptions of normal and abnormal seedlings. The optimun temperature for seed germination was $30^{\circ} \mathrm{C} ; 20$ and $35^{\circ} \mathrm{C}$ caused a decrease of percentage and speed of germination; they did not germinate in the dark and required consecutive days of light exposure to achieve maximun percentage. The seedlings to the phaneroepigeal type, which is characteristic from pionner species of large gaps.

Key-words: Germination, temperature, light, seedling.

\section{Introdução}

Tibouchina moricandiana (D.C.) Baill. é uma espécie arbórea pertencente a

\footnotetext{
'Trabalho apresentado no XLIII Congresso Nacional de Botânica, Aracajú-SE.

2Jardim Botânico do Rio de Janeiro, Área de Sementes e Mudas. Rua Pacheco Leão 915 - CEP 22460-030, Rio de Janeiro-RJ, Brasil.
} 
Melastomataceae, com distribuição exclusiva na Mata Atlântica e de ocorrência frequente em clareiras de florestas e áreas de vegetação secundária recente. Por ser rústica e heliófila, existe grande interesse em sua caracterização cultural, visando sua utilização na recuperação de áreas degradadas.

Segundo Baumgratz (1983-1985), Melastomataceae é representada na flora brasileira por 69 gêneros e cerca de 1500 espécies. Dentre as muitas espécies conhecidas desta família, algumas apresentam potencial econômico, como o jacatirão (Miconia cinnamomifolia (DC.)), sendo explorada de forma seletiva e manejada em sua regeneração natural em alguns estados da região sul do Brasil, pelas características de sua madeira (Kageyama \& Reis, 1993). Outras espécies vêm sendo utilizadas na recuperação de áreas degradadas, principalmente pela rusticidade que apresentam (Lorenzi 1992).

A luz e a temperatura são os fatores ambientais de maior importância na promoção da germinação de sementes dormentes em solos úmidos. Para muitas espécies, se fornecidas as condições ideais de luz e umidade, a temperatura predominante do solo determina tanto a fração de sementes germinadas de uma amostra, como a sua velocidade de germinação. A fração de sementes que germina, freqüentemente permanece constante dentro de uma grande amplitude de temperaturas e decresce rapidamente para valores abaixo e acima dessa mesma amplitude (Heydecker, 1977).

Conforme Dau \& Labouriau (1974) e Labouriau \& Pacheco (1978), os limites extremos de temperatura de germinação fornecem informações de interesse biológico e ecológico, onde sementes de diferentes espécies apresentam faixas distintas de temperatura para a germinação. Dentro dessas faixas, pode ser considerada como temperatura ótima aquela na qual a mais alta porcentagem de germinação é obtida, dentro do menor espaço de tempo. Seriam consideradas ainda a mínima e a máxima, respectivamente, como a mais baixa e a mais alta temperatura onde a germinação ocorre (Mayer \& Poljakoff-Mayber 1989).

Em relação ao fator luz, as sementes de muitas espécies cultivadas apresentam alta germinação tanto em presença como em ausência de luz. Entretanto, o estímulo luminoso à germinação é bastante variável para sementes de muitas espécies selvagens (Mayer \& Poljakoff-Mayber 1989). Dessa forma, as sementes foram classificadas em 3 grandes grupos, com relação a sua resposta de germinação ao estímulo luminoso: fotoblásticas positivas, que não germinam no escuro e são produzidas principalmente por plantas heliófitas (as quais requerem luz solar intensa para crescer); fotoblásticas negativas, cuja germinação é inibida pela luz, e indiferentes à luz, produzidas principalmente por plantas umbrófitas (Orozco-Segovia \& Vázquez-Yanes 1992).

Com o objetivo de conhecer melhor os mecanismos que promovem a germinação e o estabelecimento de plântulas desta espécie, este trabalho se propõe a avaliar o efeito da luz e da temperatura sobre a germinação de sementes de Tibouchina moricandiana (D.C.) Baill., assim como conhecer a morfologia do desenvolvimento pós-seminal da espécie, como mais um elemento diferenciador à subsidiar a identificação taxonômica da espécie e ainda para o estabelecimento da plântula em futuras prescrições da espécie em manuais de análise de sementes. 


\section{Material e métodos}

Sementes frescas de Tibouchina moricandiana (DC) Baill. foram obtidas a partir de frutos maduros, coletados na Reserva Ecológica Municipal de Macaé de Cima (RJ), sendo armazenadas por cinco dias sob ausência de luz, a $15^{\circ} \mathrm{C}$ e $45 \%$ de U.R.

De acordo com o fatorial 4 × 2, estudou-se a influência de cinco diferentes temperaturas $\left(20,25,30,35\right.$ e $\left.30-20^{\circ} \mathrm{C} \pm 0,5^{\circ} \mathrm{C}\right)$ sob condição de escuro contínuo e fotoperíodo de 8 horas, sobre a germinação de sementes. Os testes de germinação foram conduzidos em placas de Petri contendo 25 sementes, as quais foram semeadas sobre duas folhas de papel de filtro umidecidos com água destilada, com quatro repetições por tratamento. Os experimentos foram realizados em câmaras de germinação do tipo B.O.D., iluminadas com lâmpadas fluorescentes do tipo "luz do dia" (4 x $20 \mathrm{~W}$ ), com densidade do fluxo radiante na altura das placas de $15 \mu \mathrm{mol} \cdot \mathrm{m}^{-2} \cdot \mathrm{s}^{-1}$, medidas com quantum radiômetro Li-Cor (LiCor Inc., Lincoln, Nebrasca).

O critério utilizado para avaliar a germinação foi a protusão conspícua da radícula, sendo verificada diariamente para o tratamento 8 horas de luz. Na condição de escuro contínuo, as placas de Petri foram inseridas em embalagens de polietileno preta com camada interna de papel aluminizado, com a germinação avaliada somente ao final do experimento. O índice de velocidade de germinação (IVG) foi determinado de acordo com o critério estabelecido por Czabator (1962), contando-se diariamente o número de sementes germinadas até o décimo-sexto dia após a semeadura.

Os valores em porcentagem foram transformados em arco seno (\%/100)1/2 para normalização de sua distribuição (Bartlett 1947). Os resultados foram avaliados estatisticamente, onde foi adotado o delineamento inteiramente casualizado, em esquema fatorial. Foi utilizado o teste de Tukey, ao nível de 5\% de probabilidade, para comparação entre as médias, quando houve significância pelo teste F (Steel \& Torrie 1980).

As observações diárias da germinação permitiram o acompanhamento e descrição morfológica do desenvolvimento pós-seminal. As ilustrações foram feitas com auxílio de estereomicroscópio com aumento de até 5 vezes, equipado com câmara clara. Critérios pré-estabelecidos para caracterização da plântula normal basearam-se em Brasil (1992); a terminologia para descrições das estruturas essenciais da plântula seguiram Stearn (1983).

\section{Resultados e discussão}

Para todos os tratamentos testados, as sementes foram submetidas a 24 horas de embebição sob ausência de luz e a temperatura de $25^{\circ} \mathrm{C}$, já que para muitas sementes fotoblásticas positivas, a germinação só se inicia após decorrido certo período de embebição sob ausência de luz. Este período de embebição no escuro pode ser necessário para que o fitocromo seja transformado em sua forma ativa Fve, pois em 
tecidos desidratados a fototransformação pode não ocorrer (Wulff \& Medina 1969, Takaki et al. 1981).

A germinação de sementes de Tibouchina moricandiana, submetidas a diferentes temperaturas sob duas condições de luminosidade é demonstrada através da tabela 1. A temperatura de $35^{\circ} \mathrm{C}$ apresentou valores de germinação significativamente inferiores $(\mathrm{P}<0,05)$ às demais, sob fotoperíodo de 8 horas. Verificou-se que independente da temperatura testada, as sementes não germinaram quando submetidas a ausência de luz, apresentando desta forma fotoblastismo positivo para todas as temperaturas testadas.

Em relação ao índice de velocidade de germinação, os resultados mostram que a temperatura de $30^{\circ} \mathrm{C}$ apresenta valores estatisticamente superiores $(\mathrm{P}<0,05)$ as temperaturas 20 e $35^{\circ} \mathrm{C}$ (Tabela 1), demonstrando uma velocidade de germinação superior nesta temperatura. Estes resultados podem ser comprovados através da Figura 18, onde verificamos o desenvolvimento do processo germinativo (germinação cumulativa) durante 16 dias de avaliação para as 5 temperaturas testadas. A temperatura de $30^{\circ} \mathrm{C}$ apresentou a máxima germinação no sexto dia após a semeadura; para as temperaturas de 25 e $30-20^{\circ} \mathrm{C}$, somente após o oitavo dia verificou-se a máxima germinação das sementes. Para as demais temperaturas, após 16 dias foram obtidos os pontos de máxima germinação. Estes resultados demonstram que a germinação em sementes de Tibouchina moricandiana ocorre dentro de uma ampla faixa de temperaturas $\left(20\right.$ até $\left.35^{\circ} \mathrm{C}\right)$, apresentando redução significativa em sua velocidade de germinação para as temperaturas de 20 e $35^{\circ} \mathrm{C}$.

Tabela 1. Valores médios de germinação e do índice de velocidade de germinação (I..V.G.) em sementes de Tibouchina moricandiana, submetidas a diferentes condições de luz e mantidas em diferentes regimes de temperatura.

\begin{tabular}{ccccc}
\hline Temperatura $\left({ }^{\circ} \mathrm{C}\right)$ & \multicolumn{3}{c}{ Germinação $(\%)$} & \multicolumn{2}{c}{ I.V.G. } \\
\hline & \multicolumn{1}{c}{ luz } & escuro & luz & escuro \\
\hline 20 & $55,6 \pm 5,4 \mathrm{ab}{ }^{\prime}$ & 0 & $32,7 \pm 10,5 \mathrm{~b}$ ' & 0 \\
25 & $65,9 \pm 10,4 \mathrm{ab}$ & 0 & $56,2 \pm 20,2 \mathrm{ab}$ & 0 \\
30 & $68,9 \pm 15,4 \mathrm{a}$ & 0 & $80,2 \pm 27,6 \mathrm{a}$ & 0 \\
35 & $48,2 \pm 5,0 \mathrm{~b}$ & 0 & $25,5 \pm 8,2 \mathrm{~b}$ & 0 \\
$30-20$ & $61,9 \pm 4,0 \mathrm{ab}$ & 0 & $57,2 \pm 7,2 \mathrm{ab}$ & 0 \\
$\mathrm{~F}$ & & $3,30 *$ & $6,80 * *$ & \\
$\mathrm{CV}(\%)$ & 17,80 & 33,20 & \\
\hline
\end{tabular}

**** Significativo a 5 e $1 \%$ de probabilidade, respectivamente.

' Médias seguidas de mesma letra não diferem significativamente entre si, ao nível de $5 \%$ de probabilidade.

O efeito da luz sobre a dormência de sementes de algumas espécies parece estar diretamente relacionado com a temperatura testada (Bewley \& Black 1985). Em sementes de Hyoscyamus desertorum, a ação da luz na quebra de dormência foi 
alterada pelo aumento da temperatura (Roth-Bejerano et al. 1971). Os autores verificaram que a germinação sob ausência de luz alcançou valores superiores a $20 \%$ nas temperaturas de 25 e $35^{\circ} \mathrm{C}$. Todavia, nas temperaturas de 10,15 e $20^{\circ} \mathrm{C}$, a germinação foi nula para a mesma condição de luminosidade.

Em sementes de Tibouchina moricandiana, as temperaturas testadas apresentaram pouca influência sobre o requerimento de luz, já que as mesmas não promoveram a germinação sob condição de escuro; as sementes mantiveram uma dormência forçada (germinação nula) para todas as temperaturas, havendo uma promoção na germinação somente após exposição à luz durante 8 horas por dia (Figura 18). Em alguns casos, tratamentos utilizando temperaturas alternadas podem estimular a germinação sob ausência de luz em sementes fotoblásticas positivas, como é o caso de Poa pratensis (Toole \& Borthwick 1971). Em sementes de Tibouchina moricandiana, verificou-se que a temperatura alternada de $30-20^{\circ} \mathrm{C}$ não estimulou a germinação de suas sementes quando submetidas a ausência de luz.

Sementes de espécies pioneiras arbóreas apresentam basicamente dois tipos de dormência forçada: dormência fotoblástica e dormência regulada pela temperatura (Vazquez-Yanes \& Orozco-Segovia 1982). No primeiro caso, o fitocromo nas sementes atua como um sensor ambiental, detectando no espectro luminoso a proporção entre os comprimentos de onda de vermelho/vermelho-extremo da luz incidente. Este processo ocorre por exemplo em sementes de Cecropia glaziovii (Valio \& Joly 1979), espécie muito frequente em florestas secundárias e áreas de clareira, onde a luminosidade apresenta uma alta proporção de V/VE. Neste caso, o processo germinativo só é iniciado após decorrido certo período de exposição à luz. No segundo caso de dormência forçada, sementes que apresentam seu tegumento impermeável a água têm sua germinação estimulada pelas flutuações de temperatura produzidas na superfície do solo, as quais tornam permeável o tegumento através de fissuras provocadas pela contração e expansão deste tecido com a variação de temperatura.

Dos tipos de dormência citados acima, a luz parece ser o agente que estimula o processo germinativo das sementes de muitas espécies de Melastomataceae. Em sementes de Miconia cinnamomifolia, tanto sementes provenientes de frutos imaturos como de frutos maduros apresentaram germinação nula em ausência de luz. Verificouse um fotoblastismo acentuado quando, uma vez expostas a luz branca contínua, os valores de germinação foram superiores a 50\% (Queiroz 1982). Resultados semelhantes foram encontrados por Pinto et al. (1983) para sementes de Tibouchina fothergillae, onde os autores verificaram uma porcentagem de germinação significativamente superior para sementes mantidas em presença de luz em comparação com sementes mantidas sob condição de escuro. Barbosa et al. (1988), estudando o efeito de diferentes períodos de luz e temperaturas sobre a germinação de sementes de Tibouchina sellowiana, obtiveram resultados semelhantes em relação ao presente trabalho, onde as sementes apresentaram fotoblastismo positivo, tendo como ideal a temperatura de $30^{\circ} \mathrm{C}$.

O estudo morfológico do desenvolvimento pós-seminal permitiu o conhecimento das estruturas essenciais da plântula a partir da emergência da radícula (Figura 1) 


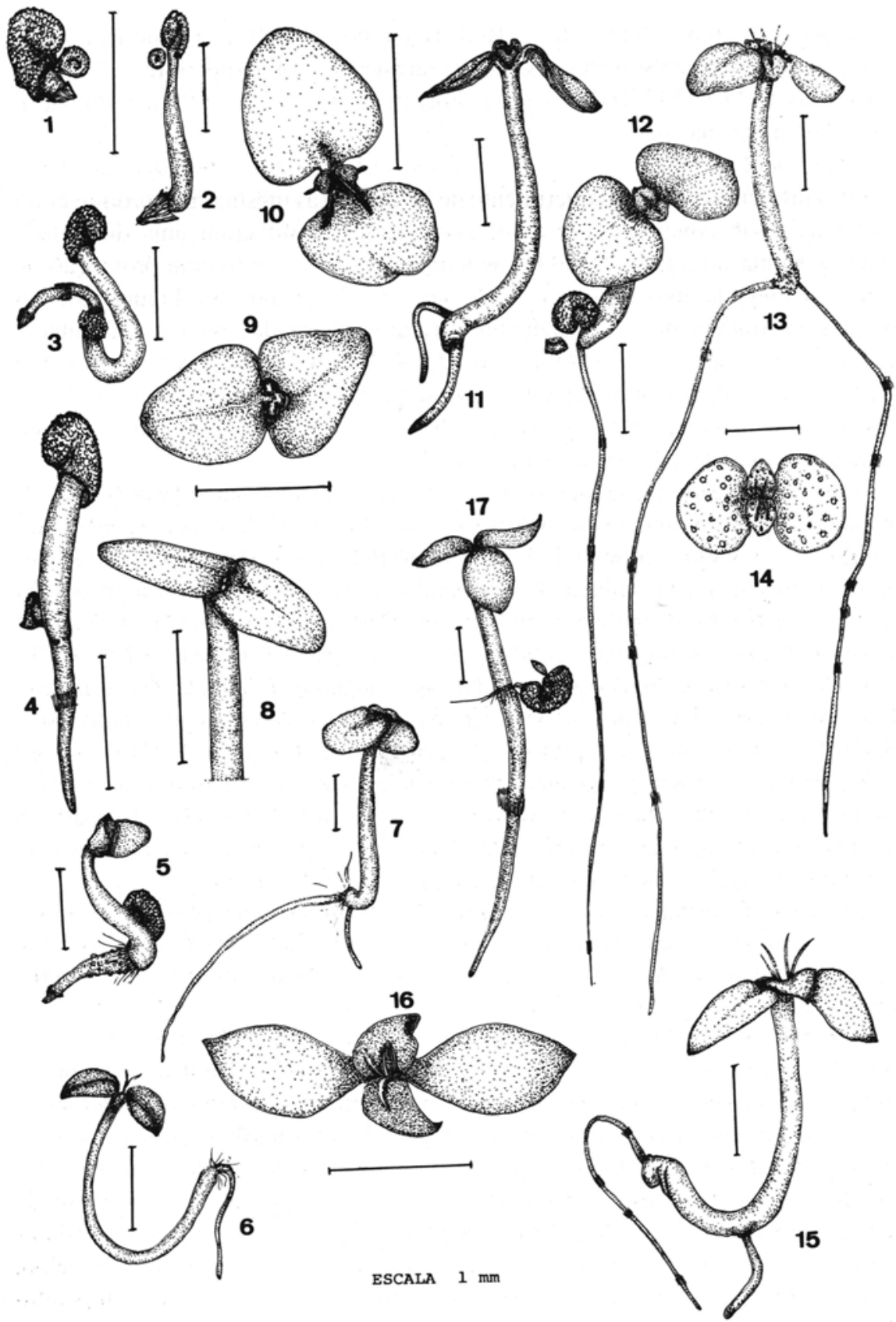

Tibouchina moricandiana (DC) Baillon - Figuras 1 a 7 - Fases do desenvolvimento pós-seminal; Figuras 8 a 10 - Dêtalhe dos coltilédones e gema apical; Figuras 11, 12, 13 e 15- Plântula normal; Figuras 14 e 16 - Detalhe dos cotilédones e eófilos; Figura 17-Plântula com 3 cotilédones. 


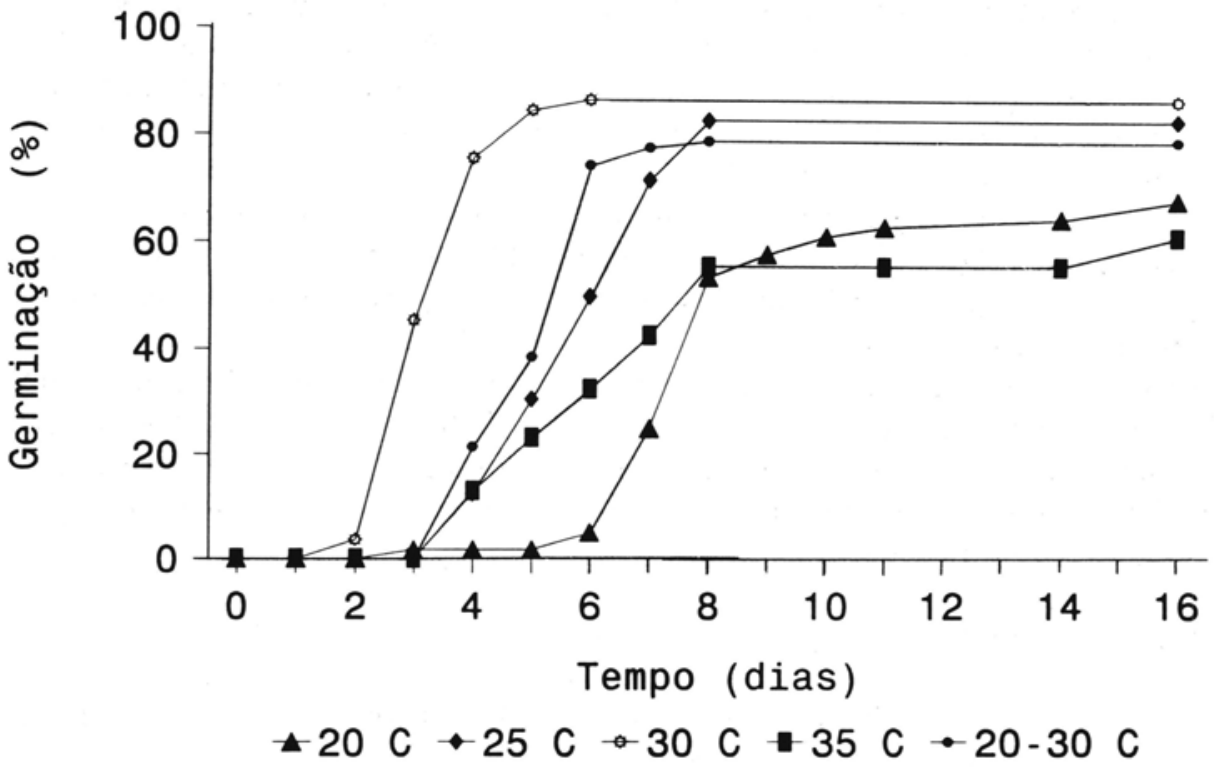

Figura 18. Efeito da temperatura na germinação de sementes de Tibouchina moricandiana (DC) Baill., mantidas sob fotoperiodo de 8 horas de luz.

que ocorreu dos $2 / 3$ dias após a semeadura; apesar das reduzidas dimensões da plântula antes da emergência dos cotilédones (Figuras 2,4), foi possível verificar que o ápice da raiz principal em desenvolvimento apresenta uma coifa conspícua (Figuras 2,3 ), protegendo o meristema radicular. A região do colo é bem delimitada nos estádios iniciais por uma densa granulação, acompanhada por um anel de pelos (Figuras 3, 5).

A emergência dos cotilédones ocorre aos 6/7 dias do desenvolvimento (Figura 5) e a sua expansão total (Figura 7) ocorre aos 8/9 dias. Aos 10/11 dias nota-se o aparecimento da plúmula diminuta (Figura 8).

A plântula com todas as suas estruturas essenciais se estabelece aos 20/25 dias do processo e se apresenta com 2 a $5 \mathrm{~mm}$ de altura (com exceção das raízes), de coloração verde-rosada.

De acordo com Duke (1969) a germinação onde os cotilédones expandidos são elevados pelo alongamento do hipocótilo é designada fanerocotiledonar. A plântula de Tibouchina moricandiana se enquadra melhor, entretanto, no tipo faneroepígea (Duke \& Polhill 1981), pois apresenta o hipocótilo cilíndrico elevando o par de cotilédones de forma obovada a elíptica, curto peciolados com a plúmula desenvolvida em um par de eófilos sésseis também de forma obovada a elíptica, com 2 pares de pêlos longos unisseriados na base da lâmina (Figuras 13,14, 15, 16). As raízes, longas e filiformes, apresentam restos das coifas perfuradas ao longo do comprimento (Figura $12,13,15)$. 
É possível classificar ainda a plântula de Tibouchina moricandiana, segundo Vogel (1980), como sendo do tipo Maracanga, com cotilédones expandidos elevados pelo hipocótilo acima do nível do solo, fotossintetizantes e efêmeros. O autor cita que plântulas com estas características são típicas de áreas abertas, ou seja ocorrem em clareiras.

Vogel (1980) afirma ainda que os estádios juvenis das plantas, particularmente das espécies arbóreas, são frequentemente tão diferentes dos estádios adultos que mesmo com bom conhecimento das espécies no campo é dificil correlacionar as plântulas com o adulto. Constatou-se ser este o caso da plântula Tibouchina moricandiana, cujo reconhecimento no campo torna-se difícil devido ao seu reduzido tamanho e pelas diferenças morfológicas das estruturas que não permitem a sua comparação com os indivíduos adultos da mesma espécie, sendo necessário acompanhar o desenvolvimento até estádios mais avançados para verificar as modificações até indicação de formação de estruturas definitivas.

\section{Agradecimentos}

Os autores agradecem a Ana Paula Martins Cruz Fernandes por sua atenção na condução das análises de germinação.

\section{Referências bibliográficas}

Barbosa, J. M.; Barbosa, L. M.; Pinto, M. M. \& Aguiar, I. B. 1988. Efeito do substrato, temperatura e luminosidade na germinação de sementes de quaresmeira. Revista Brasileira de Sementes, 10(3): 69-77.

Bartlett, M. S. 1947. The use of transformations. Biometrics, 3: 39-52.

Baumgratz, J. F. A. 1983-1985. Morfologia dos frutos e sementes de Melastomataceas brasileiras. Arquivos dò Jardim Botânico do Rio de Janeiro, 27: 113-155.

Bewley, J. D. \& Black, M. 1985. Seeds: Phisiology of development and germination. NewYork: Plenum Press.

Brasil.1992. Ministério da Agricultura e Reforma Agrária. Regras para Análise de sementes. Brasília: LAVARV/SNAD/MA.

Czabator, F. J. 1962. Germination value: an index combining speed and completness of pine seed germination. Forest Science, 8: 386-396.

Dau, L. \& Labouriau, L. G. 1974. Temperature control of seed germination in Pereskia aculeata Mill. An. Acad. Bras. Cien., 46: 311-322.

Duke, A. 1969. On Tropical Tree Seedlings. I. Seeds, seedlings, systems and systematics. Ann. Miss. Bot.Gard. 56: 125-161.

Duke, A \& Polhill, R. M. 1981. Seedlings of Leguminosae. In: Polhill, R. M. (ed.) Advances in Legume Systematics, Kew, Royal Botanic Gardens, Vol.2, p.291-949.

Heidecker, W. 1977. Stress and seed germination: an agronomic view. In: Khan, A. (ed.). The physiology' and biochemistry of seed dormancy and germination. Amsterdam: Elsevier. p. 237-282.

Kageyama, P. \& Reis, A. 1993. Areas of secondary vegetation in the Itajai Valley Santa Catarina, Brasil: Perspectives for management and conservation. Forest Genetic Resources Information, 21: 37-41.

Labouriau, L. G. \& Pacheco, A. 1978. On the frequency of isothermal germination in seeds of Dolichos biflorus L. Plant \& Cell Physiol., 19: 507-512.

Lorenzi, H. 1992. Árvores Brasileiras. São Paulo: Ed. Plantarum. 
Mayer, A. M. \& Poljakoff-Mayber, A. 1989. The germination of seeds. Oxford: Pergamon Press.

Orozco-Segovia., A \& Vazquez-Yanes, C. 1992. Los sentidos de las plantas: La sensibilidad de las semillas a la luz. Ciencia, 43: 399-411.

Pinto, M. M.; Barbosa, J. M. \& Silveira, R. B. A. 1983. Contribuição à caracterização cultural de Tibouchina fothergillae Cogn. In: Anais 4. ${ }^{\circ}$ Congresso da Sociedade Brasileira de Floricultura e Plantas ornamentais. Rio de Janeiro, RJ. p. 179-186.

Queiroz, M. H.1982. Aspectos preliminares de beneficiamento e germinação de Miconia cinnamomifolia. In: Anais Congresso Nacional sobre Essências Nativas. Campos do Jordão, SP. p. 318-321.

Roth-Bejerano, N.; Koller, D. \& Negbi, M. 1971. Photocontrol of germination in Hyoscyamus desertorium, a kinetic analysis. Israel Jounal of Botany, 20: 28-40.

Stearn, W.T. 1982. Botanical Latin, New York: Hafner Publ. Co.

Steel, R. G. D. \& Torrie, J. H.1980. Principles and procedures of statistics. A biometrical approach. New York: McGraw Hill.

Takaki, M.; Kendrik,R. E. \& Dietrch, S. M. C. 1981. Interaction of light and temperature on germination of Rumex obtusifolius L. Planta, 152: 209-214.

Toole, V. K. \& Borthwick, H. A. 1971. Effect of light, temperature and their interactions on germination of seeds of Kentucky Blue Grass (Poa pratensis). Journal of the American Society of Horticultural Science, 96: 301-306.

Valio, I. F. M. \& Joly, C. A. 1979. Light sensitivity of the seeds on the distribution of Cecropia glaziovii S. (Moraceae). Z. Pflanzenplyysiol., 91: 371-376.

Vazquez-Yanes, C. \& Orozco-Segovia, A. 1982. Seed germination of a tropical rain forest pioneer tree (Heliocarpus donellsmithii) in response to diurnal flutuations of temperature. Physiol. Plant., 65: 295-298.

Vogel, E. F. de. 1980. Seedling of dicotyledons. Netheerlands, Center Agric. Publ. Doc. Wagerningen.

Wulff, R. \& Medina, E. 1969. Germination of seeds in Jussiaea suffruticosa. Plant Cell Physiology, 10: 503-511. 